\title{
Risk communication and the social amplification of risk
}

\section{ORTWIN RENN}

"Fish may die or human beings; drinking water or swimming in rivers or lakes may cause diseases; we may run out of oil; the global temperature may rise or fall; all these effects will not cause any societal effects unless society communicates about it. Society is sensitive to the natural environment, but it operates as a closed system. Society observes nuture and environment through communication. Communicating meaning is the only means for initiating responses: therefore it can regulate communication only by other forms of communication. In essence, it is society which poses a threat to its survival, not the environment."

(Niklas Luhmann 1986, p. 63; Translation by author)

Most societies have become highly preoccupied with the notion of risk. The interest of public institutions and academia in risk communication has considerably grown during the last five years. Accordingly, risk communication has become a popular topic in the literature. Although originally conceptualized as a follow-up of risk perception studies, the work on risk communication has surpassed the limited boundaries of giving public relation advice for information programs on risk and extended its focus on the flow of information between subsystems of society (Jasanoff 1987, p. 116; Zimmermann 1987, p. 131; Kasperson 1986, p. 275).

The interactions of social groups about risk-related issues are potential amplifiers or attenuators of communication signals. Therefore, the concept of social amplification of risk may be an interesting and rewarding framework for analyzing risk communication The main thesis of the social amplification concept is that events pertaining to hazards interact with psychological, social, institutional, and cultural processes in ways that can heighten or attenuate public perceptions of risk and shape risk behavior. Behavioral patterns, in turn, generate secondary social or economic consequences. These consequences extend far beyond direct harms to include significant indirect impacts, e.g. liability, insurance costs, loss of confidence in institutions, or alienation from community affairs (Kasperson et al. 1988, p. 181). Under certain circum- 


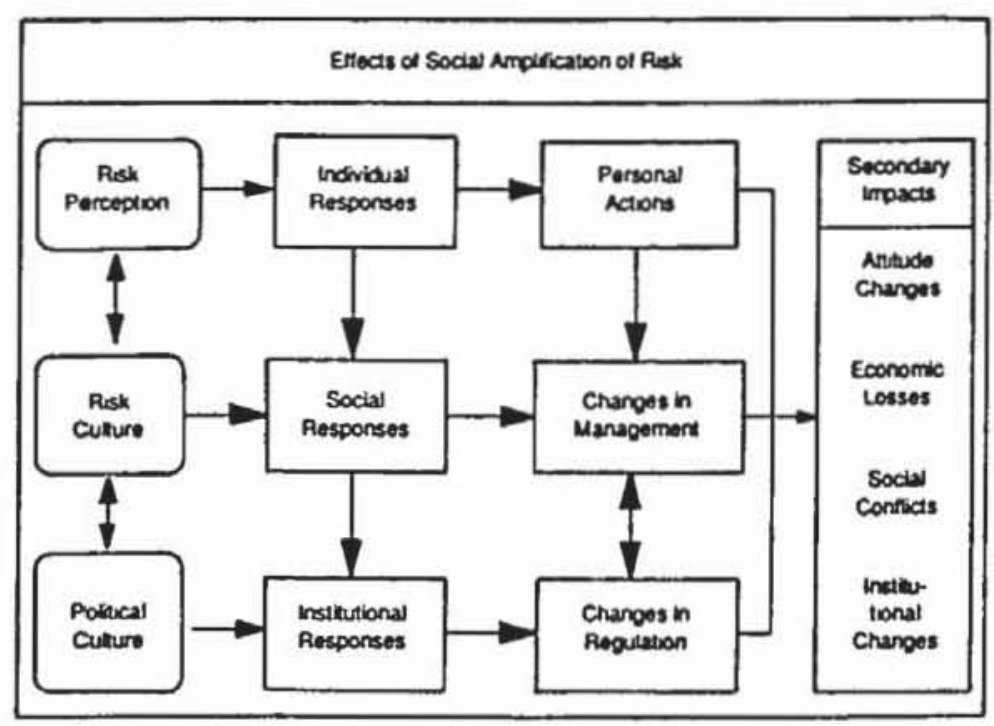

Fig. 13.1. Effects of social amplification of risk. Specialized subsystems of society, such as scientific labs or agencies, search for physical signals about hazards or hazardous events and transform these signals into communicative messages. These messages are further transformed by professional transmitters and elicit responses from individuals and groups. The types and intensity of responses are a product of the amplification mechanisms in each step of the transformation. The responses lead to secondary and tertiary effects which in turn may have repercussions on political structure, social change and technological adjustments.

stances, they may also act to increase or decrease the physical risk. Figure 13.1 illustrates a schematic sequence of the impacts of a hazardous event including the feedback for managing future hazardous events.

The consequences of an hazardous event are perceived by individuals. These perceptions lead to personal and social responses depending on the personal values and convictions of the individuals and the social images and norms pertaining to the cultural interpretation of this event in a specific social situation and context (risk culture). Behavioral responses evoke institutional reactions and regulatory changes, which in turn act as agents for new risk management efforts and changes of protective actions. Thus the social process of risk perception, behavioral responses, and institutional adaptations to political pressure may alter the nature and intensity of the physical hazard.

The focus of the social amplification concept is not so much directed toward the links between risk management and social responses, but toward the connection between the social experience of risk, behavioral responses, and secondary consequences relating to economic, legal, social, or institutional changes. Such secondary effects cause additional demands for institutional responses and protective actions, or, conversely (in the case of risk attenuation), place impediments in the path of needed protective actions. The interactions between the different actors in the social arena of the risk debate, 
the repercussions on individual and social responses in this arena and in the general public, and the implications of these responses for risk management are the central elements of the framework that we have termed "The Social Amplification of Risk" (Kasperson et al. 1988, p. 180). A case study of how to apply this concept for nuclear waste disposal has been published in Kasperson et al. (1988).

Social Amplification of risk denotes the phenomenon by which information processes, institutional structures, social group behavior, and individual responses shape the social experience of risk, thereby contributing to risk consequences. In accordance with the metaphor of amplification in electronic signal processing, amplification includes both, intensifying and attenuating signals about risk. Thus, alleged overreactions of target audiences should receive the same attention as alleged down-playing (see the critical remarks about the focus on overreactions in most risk communication analyses in: Needleman 1987 , p. 20). Although the term "amplification" carries a common connotation of strengthening signals (cf. Rip in his comment on this problem, 1988, p. 196), we adhere to the metaphor because it provides a powerful and lucid illustration of our model. But in contrast to public understanding of amplification, we are equally interested in attenuation, and not only in intensification of signals.

Some terms in our definition need further explanation. When we talk about risks, we conceptualize it as social construct and not as an objective property of a hazard or event (cf. Johnson and Covello 1987; Jasanoff 1987). Risk is in part a product of social experience, including communication about potential consequences of a potentially hazardous event or series of events. If any of these anticipated or modelled events manifest themselves in form of accidents, emissions, health effects, or other physical transformation, we term these manifestations of risk as "hazardous events". Hence, hazardous events are "real": they resemble transformations of the physical environment or human health as a result of continuous or sudden (accidental) release of energy or matter. These events remain largely irrelevant in the social context unless they are observed by human beings and communicated to others (Luhmann 1986, p. 63). The consequences of these communication efforts may finally lead to other physical transformations, such as changes in technologies, changes in methods of land cultivation, or changes in the composition of water, soil, and air.

Many aspects of the complex social processes involved in this framework require analysis. In this chapter we explore the particular role of social communication. The basic principles of our concept of social amplification of risk may appear obvious. But the virtue of the concept is that it provides an analytical framework capable of integrating the competing perspectives of individualistic (risk perception), structuralistic (cultural theory of risk, and 
some sociological and Marxist approaches), and constructivist (social construct theory) concepts. It represents a flexible and logical framework for the analysis of the relationships among individual, social, and political responses to risks. By focusing on signal transformation and its effect on social structure and environment, the concept avoids the exclusiveness of either the individual or the social aggregate as basic unit of analysis. Communication occurs on the individual, group, and social level (Micro, Meso, and Macro perspective).

\section{Conceptual framework}

Definition of risk communication: For our analysis, we decided to adopt the definition of risk communication suggested by Covello, von Winterfeldt, and Slovic: "Risk communication is defined as any purposeful exchange of information about health or environmental risks between interested parties. More specifically, risk communication is the act of conveying or transmitting information between parties about (a) levels of health or environmental risks; (b) the significance or meaning of health or environmental risks; or (c) decisions, actions, or policies aimed at managing or controlling health or environmental risks. Interested parties include government agencies, corporations and industry groups, unions, the media, scientists, professional organizations, public interest groups, and individual citizens" (Covello, 1986, p. 172).

Plough and Krimsky have criticized this definition (using a different reference, however) as being too narrow and technical $(1987$, p. 6). They prefer a broader understanding of risk communication that includes unintentional messages, other dimensions beyond health and environment, no restrictions on audiences and a flow of message from any source to any recipient through any channel (p. 7). We agree that the definition should not constrain information flow and target audiences. However, we see no conflict in this respect with the definition of Covello et al. above. Neither the direction of the communication process is specified, nor is any target audience excluded. We have objections, however, with the two former proposals of including the exchange of information without any specified purpose and of enlarging the dimensions of risk beyond health and environment.

Social communication is usually defined as a purposeful exchange of information between actors in society based on shared meanings of the transferred messages (DeFleur and Ball-Rokeach 1982, p. 133). A purpose is required to distinguish the sending of a message from noise in the communication channel. The intentions of the sender may or may not be part of the message, hidden agendas may obscure the stated goal in the message, and the intended meaning may not be understood; but actors in social communication 
send out information as a means to obtain a specific personal or institutional goal. The term "message" implies that the informer intends to expose the target audience to a system of meaningful signals, which in turn may change the perception of the issue for the sender. This does not imply, however, that the receiver actually perceives the whole message or knows the intention behind the message. In complex societies, purposeful information and noise form a symbiotic relationship which makes it hard to predict the effects of messages on the final recipient.

The second question of whether to define risk in a broad or narrow sense is purely a matter of personal discretion or professional convention. We prefer the narrow definition for four reasons:

1. There is a broad agreement among risk analysts to confine risk consequences to adverse effects on health and environmental quality (National Research Council 1981; Rowe 1977; Lowrance 1976)

2. The broader the risk concept is defined the more difficult it is to draw a formal distinction between risk analysis and other impact assessments, such as technology assessment, social impact analysis, future studies, and others.

3. Because the structure of social systems and their interactions with the physical environment are characterized by a degree of complexity and dynamics that any scientific model is never capable of reproducing or simulating, simplification is essential and a limitation in range seems more appropriate than one in depth. A confinement to health hazards and environmental quality promises more valid results than expanding the range of impacts to all imaginable probabilistic consequences.

4. Our interest in the social and cultural context of risk communication would be unmanageable to study if we had to deal with all potential impact categories simultaneously.

The limitation to health and environment does not exclude the study of secondary social and political effects (based upon the communication on health and environmental risks), and of the circumstances, qualitative characteristics, and social arenas of risk communication. The same understanding of risk communication is also expressed by Fiskel and Covello in their listing of elements of risk communication (Fiskel and Covello 1987, p. 90).

Many risk communication studies focus primarily on the two classical components of risk: probabilities and magnitude. We are convinced, however, that the other risk-related factors are at least as important as the components of technical risk analyses. Empirical studies about media coverage of risk events confirm this assumption (Rubin 1987; Otway et al. 1986; Sood, Stockdale, and Rogers 1987; Wilkins and Patterson 1987; Peltu 1989) as well as studies about regulatory decisions on priorities (Allen 1987, p. 140). 
Objectives of risk communication: Since we defined risk communication as an intentional information transfer, we have to specify what kind of intentions and goals are associated with most risk communication efforts. The literature offers different sets of objectives for risk communication, usually centered on a tisk management agency as the communicator and groups of the public as target audiences (Covello, von Winterfeldt, and Slovic 1986, p. 172; Kasperson and Palmlund 1987, p. 4; Zimmermann 1987, pp. 131-132). Although most lists have quite a substantial number of entries for risk communication objectives, they can mostly be reduced to the following four items:

1. inducing changes in knowledge, opinions, or attitudes;

2. encouraging protective behavior by individuals and groups;

3. creating trust and confidence in risk management institutions; and

4. assisting conflict resolution and public involvement.

For our comprehensive analysis of risk communication as the major pathway of social amplification, the list of objectives have to be sub-structured in a slightly different manner. It is necessary to distinguish between micro-, meso-, and macro-level. This requires a classification of functional objectives according to the information flow from one level to another. Communication occurs among individuals, between groups and individuals, among groups, between political institutions and social groups, between political institutions and individuals, and among institutions of the political system.

The resulting three times three matrix (see Table 13.1) defines the range of inter-level and intra-level communication. Each cell of the matrix represents a communication situation in which the sender or the receiver are located in one of the three levels of analysis: individuals, social groups, or political institutions. Classifying these situations provides us with a systematic approach to link communication functions with communication structure and to avoid the obvious restriction of many communication studies which focus exclusively on the information process between agencies and individuals. Communication, however, occurs on all three levels and serves different functions depending on which level is addressed. By analyzing each row of Table 13.1, we can define these functions and discuss their relevance.

Row 1: Individuals may engage in risk communication with the intention to inform others about potential hazards, persuade them to take protective actions or mitigate the potential consequences. Also, individuals may try to convince their fellow citizens that specific risks are worth taking (risk acceptance). If individuals address groups, they intend either to influence the position of the group, inform the group members about a hazard, request support for risk reduction or initiate political actions. In the rare cases that individuals 
seek to interact with government institutions or agencies directly, they want to influence risk policies or convey their perception of the problem to the respective institution.

Row 2: Risk communication originated by social groups is certainly more intense and influential. The addressees of this risk communication are individuals, other groups, and political institutions. Social groups approach individuals, for example residents near a chemical plant, for a variety of reasons: they want to inform and educate them about the risks, they may give advice for risk reduction behavior, particularly for emergencies, or they may try to enhance

Table 13.1. Objectives of risk communication and levels of analysis.

\begin{tabular}{|c|c|c|c|}
\hline From/to & $\begin{array}{l}\text { MICRO-LEVEL } \\
\text { Individual }\end{array}$ & $\begin{array}{l}\text { MESO-LEVEL } \\
\text { Groups }\end{array}$ & $\begin{array}{l}\text { MACRO-LEVEL } \\
\text { Society }\end{array}$ \\
\hline Individual & $\begin{array}{l}\text { Persuation for } \\
\text { risk reduction } \\
\text { Risk acceptance } \\
\text { Education }\end{array}$ & $\begin{array}{l}\text { Influence on group } \\
\text { decision } \\
\text { Request for support } \\
\text { Education }\end{array}$ & $\begin{array}{l}\text { Change of risk policies } \\
\text { Request for support } \\
\text { Information }\end{array}$ \\
\hline Group & $\begin{array}{l}\text { Education } \\
\text { Support } \\
\text { Persuasion for } \\
\quad \text { risk reduction } \\
\text { Risk acceptance } \\
\text { Acceptance of } \\
\text { risk management } \\
\text { Trust in group's } \\
\text { competence }\end{array}$ & $\begin{array}{l}\text { Education } \\
\text { Coalition } \\
\text { Conflict resolution } \\
\text { Prestige } \\
\text { Acceptance of } \\
\text { risk management } \\
\text { Trust in group's } \\
\text { competence }\end{array}$ & $\begin{array}{l}\text { Information } \\
\text { Influence on risk policies } \\
\text { Acquisition of } \\
\text { social resources } \\
\text { Change in risk culture } \\
\text { Compliance with } \\
\text { risk standards } \\
\text { Development of } \\
\text { incentives for } \\
\text { structural change }\end{array}$ \\
\hline Society & $\begin{array}{l}\text { Risk reduction } \\
\text { Emergency response } \\
\text { Acceptance of } \\
\text { risk management } \\
\text { Trust in risk agencies } \\
\text { Loyalty with respect to } \\
\text { the risk handling } \\
\text { capacity of society }\end{array}$ & $\begin{array}{l}\text { Risk reduction } \\
\text { Emergence response } \\
\text { Acceptance of } \\
\text { risk management } \\
\text { Legitimation of } \\
\text { risk agencies } \\
\text { Loyalty with respect to } \\
\text { the risk handling } \\
\text { capacity of society } \\
\text { Mediating in conflict } \\
\text { resolution }\end{array}$ & $\begin{array}{l}\text { Strategies for risk } \\
\quad \text { management and } \\
\text { regulation } \\
\text { Agenda for risk agencies } \\
\text { Institutional reform } \\
\text { Development of new } \\
\text { paradigms of risk } \\
\text { Changes in risk culture } \\
\text { Influence on } \\
\text { international and } \\
\text { global risk policies } \\
\text { International conflict } \\
\text { resolution }\end{array}$ \\
\hline
\end{tabular}


community acceptance by drawing a positive image of the risk source, by conveying confidence in their risk management and by building trust between the affected citizens and themselves.

Groups also interact with other groups. Mutual education and information is only one goal of this communication. Usually groups try to improve their strategic position in society when communicating about risk. They may seek coalitions with other groups, attempt to improve their image by expressing concern about risks, want support for their risk management approach or intend to document their trustworthiness and competence. In addition, risk communication may be necessary to formulate and design compromises in conflicting situations.

The information flow between groups and governmental institutions is directed mainly towards changing risk policies or regulation. The pursuit of regulatory changes may induce other structural changes within the political institutions or even alter the political culture (i.e., the means, norms and values of exercising political power and of designing and responding to public policies). The ultimate goal of most groups is to change the structural rules of distribution of social resources for their own benefit. Since risk communication is focused on future gains and benefits, it is a particularly sensitive issue in the communication between the meso-level and the macro-level.

Row 3: If information is originated by governmental institutions, target audiences may be individuals (home-owners, for example, in the case of geological radon), social groups (i.e. real estate agents), or other governmental institutions (risk management agencies as well as risk-unrelated institutions). In addition to education, persuasion, and building trust and confidence in risk management agencies, one of the most relevant goals here is to assure individuals and groups that the political and regulatory system is capable and qualified to deal with hazardous agents and manage their potential impact. Such a qualification includes evidence about the openness of the decision process, the flexibility to adjust to new information or external constraints, and the resilience to master even unexpected surprises (Haefele et al., in press). In many instances, risk communication may also serve a mediating function between conflicting groups.

Special attention deserves the interaction among governmental institutions. It is not only public pressure that leads to structural changes within the body of government. The inner dynamics of agencies and the changing nature of the problem are both powerful agents of internal change. New strategies of risk management may be evoked by a new discovery found in a government laboratory. The agenda of a risk management institution may be altered due to political re-orientations or changes in the perspective of the problems. Both causes necessarily involve risk communication. Furthermore, the internation- 
al and global nature of many risks have initiated communication among different countries to coordinate risk management efforts and to monitor transnational hazards.

The complexity of the functions on the three levels may appear confusing at first glance. But the proposed taxonomy of objectives, structured according to information flows between different levels of society, provides a useful starting point to observe the effects of amplification and attenuation in the exchange of information between individuals, groups, and society. The knowledge of functions of risk communication enables us to trace those elements of communication that are predominantly effective in serving one function or another and to investigate their resonance effect on the target audience. To pursuit this idea further, a closer look into the process of communication is required.

\section{Signal transmission in social amplification}

The sender-message-receiver model: The concept of social amplification of risk is a dynamic model which does not fit perfectly in the traditional communication model of information transfer between sources, transmitters, and final receivers. This traditional model was basically developed in the late 1940 s (Shannon and Weaver 1949; Lasswell 1948). It is still the most popular framework for communication studies up to date. In a recent review of 31 communication textbooks, P.J. Shoemaker concluded that nearly half of the books used the Shannon and Weaver model (Shoemaker 1987, p. 120). The second, most popular approach was the transactional view which emphasizes the creation of shared meaning among senders and receivers. Both approaches can obviously be combined. This has been done in two of the reviewed textbooks. Although our model of social amplification is more compatible with theories of symbolic interactions, it seems advisable to use the sender-receiver model as the major reference since it offers a basic structure of the communications process to which more dynamic feedback processes can be gradually added. The simplicity of the model may be inappropriate to represent the complexity of social communication (cf. critical remarks about our communication model by Rayner (1988) and Rip (1988)); its logical structure provides, however, a good organizational principle for conducting and describing communication studies and helps to place elements of other approaches, such as the transactional or the symbolic interactionist approach into a well-structured framework.

For our purpose of supplementing the traditional source-receiver model, the definitions originally proposed by Shannon and Weaver to describe the different communication stations can still be applied. "Communication" consists of essentially five parts: 
1. "An information source which produces a message or sequence of messages to be communicated to the receiving terminal. (...)

2. A transmitter which operates on the message in some way to produce a signal suitable for transmission over the channel. (...)

3. The channel is merely the medium used to transmit the signal from transmitter to receiver. (...)

4. The receiver ordinarily performs the inverse operation of that done by the transmitter, reconstructing the message from the signal. (...)

5. The destination is the person (or thing) for whom the message is intended. (...)

6. During transmission, or at one of the terminals, the signal may be perturbed by noise" (Shannon and Weaver 1949, pp. 4-6)

The role of the transmitter in social communication was the focus of Lasswell's article published in 1948 (pp. 32-35). His classic categorization "who says what to whom, how and with what effect" has guided empirical research on communication for the last three decades (DeFleur 1966; Lee 1986, p. 150). His basic model of information transfer identifies the mass media as the major transmitters of information in society. The flow of information starts with the coding process of a message at the source station. This message is received by transmitters, decoded, then re-coded and transmitted to the next transmitter or the final receiver. Each transmitter alters the original message by intensifying or attenuating some incoming signals and adding or omitting others. The new cluster of signals is sent to the next transmitter or the final receiver who decodes and deciphers the message and evaluates the information contained therein. This information flow model is illustrated in Fig. 13.2.

Signal amplifiers in social communication: In our model of social amplification, we focus on signals as the basic unit of analysis taking into account, however, the interrelatedness of signals and signal producers. Thus signals in social interactions define a relationship between the information source, potential transmitters, and receivers. In social communication, those signals must form a meaning, otherwise they are regarded as noise. (Through random permutations, noise may also create the illusion of meaning, but we will not consider this possibility further.) A cluster of meaningful signals pertaining to the same topic is called a message.

Any change in the order of signals or alteration of the signals may change the meaning and thus the message. Changes in messages usually occur during transmission and constitute an important part of the social amplification of signals. What kind of amplification mechanisms lead to changes in messages?

1. volume effect (intensifying or attenuating messages) 


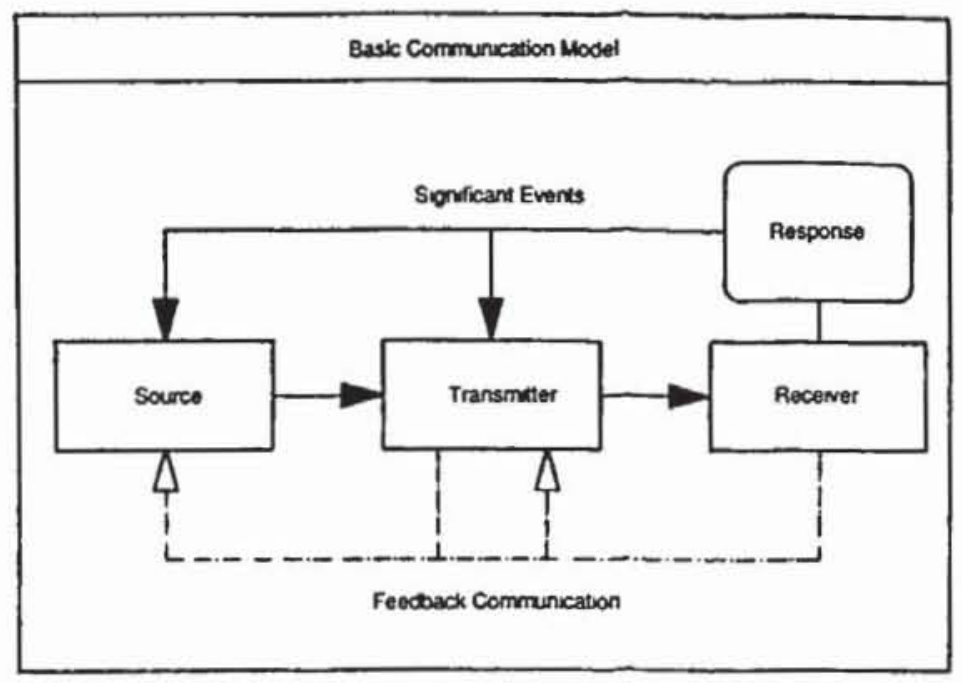

Fig. 13.2. Basic communication model. Information is generated by a source, channelled to a transmitter which amplifies and transforms the message and sends it to the final receiver. The receiver may respond to the message by starting a new communication cycle or taking actions which are also triggers for new communication efforts. Communication is therefore an escalating process of feed-backs.

2. filtering effect (intensifying or attenuating information)

3. muting and adding effect (deleting or adding information)

4. mixing effect (changing the order of presentation)

5. equalizing effect (placing the message in different contexts)

6. stereo effects (receiving the same or similar messages through different channels)

The volume effect describes the resonance a message receives after channelled to transmitters and receivers. In an analysis of media coverage of Love Canal and Three Mile Island, Mazur argues that the massive quantity of media coverage not only reported the events but defined and shaped the issues (Mazur 1984, pp. 412; cf. also Peltu 1989). Even in absence of any distortion of information, the pure volume effect has an influence on the perception of the seriousness of the message and may determine the political agenda of social groups and institutions. Conversely, the most important event may not even be recognized as anything noteworthy if it is transmitted in "low volume", i.e. on the back pages of newspapers or during unpopular broadcast periods.

The filtering effect is the degree to which partial information is highlighted or down-played. Again, the basic composition of the message may be the same (signals are neither deleted nor added), but the understanding of the meaning may be strongly influenced by partial amplification. Intensifying the informa- 
tion that the message stems from an industrial source and was not checked by the transmitter will certainly affect the credibility of the message.

The third effect, deleting or adding information, does not necessarily change the meaning of the message. If transmitters act as translators for converting scientific or agency jargon into "everyday English", they actually enhance the message and make it more intelligible for the final receiver. More frequent, however, is the case that messages are changed by adding or deleting signals. This may be done intentionally in order to create a different image than the original message implied or accidentally by attempting to shorten or lengthen the message or to make it more comprehensible to a lay audience.

Changing the order of information in messages (mixing effect) is almost routine in the news media. Conventions about what to report first (Who, when, what, why) reflect the anticipated interest of final receivers by journalists. Most of these rules of journalistic editing seem to be intuitively plausible, but as a routine procedure they may well affect the meaning of a message. An article reporting on a conference about the green-house effect due to Carbondioxid concentration may be perceived as outdated or less alarming if the conference itself took place three month before the report appeared and if this information was placed in the first sentence of the article (in accordance with the "rules").

The context in which the message is embedded (equalizing effect) is also an important factor in signal amplification. Whether the message is part of the news section of a newspaper or part of a commentary conveys a different degree of objectivity with respect to the content of the message. Lee has pointed out that messages hidden in fiction writing or entertaining movies such as "The Day After" or "The China Syndrome" may be powerful agents in creating images of objects, in particular if those images are constantly reiterated in literature and film (Lee 1986, pp. 171). The creation of images through symbolic illustrations such as flashing reactors, dramatic background music, workers with gas masks, or mushroom clouds, is part of a sublime message transfer that connects frightening or joyful symbols with an object or person (see the documentation of this context effect with regard to the media coverage of Chernobyl and Bhopal in Wilkins and Patterson 1987, p.87).

The stereo effect relates to the multitude of channels in transmitting messages. One message or topic may penetrate the information market and dominate newspapers, television, journals, and other publications. In addition to the mere volume effect, the multi-channel coverage of an issue assigns more importance and credibility to the message. In particular, if the stereo effect is well orchestrated and information sources manage to use different channels in a complimentary manner, the message will more likely reach the target audience (Pinsdorf 1987, p. 47). 
The descriptions of the effects of signal amplification demonstrates the merits, but also the limitations of using the metaphor of electronic signal theory. Although each of the social amplification effects can be expressed in terms of volume, filtering, equalizing, mixing, muting and stereo, they make only sense if the denotations of each term are adjusted to the social context. In particular, transmitters in social communication have hardly any resemblance with electronic amplifiers which allow receiver or senders to alter signals at their discretion. Instead, social transmitters are active actors in the communication process with their own, independent agendas, rules, and goals.

The function of transmitters and the interrelatedness of message and messenger has been the predominant criticism against the metaphor of amplification and the use of information theory for analyzing risk communication. In his review of our social amplification article in Risk Analysis, Steve Rayner comments:

"When a signal passes through a component, the signal is not the only element in the system to be transformed. In the case of electronic amplifiers, the changes within components do not alter the function of the equipment. Stereo systems do not become televisions. Hence, only manufacturers and inquisitive school-children are interested in what happens to a transistor or capacitor as electrons pass through (...) But in risk communication, the changes wrought in the signal bearers constantly transform the instrument; i.e. society. Human communicators are multi-functional and have the power of choice. Their experience of choices accumulates. In this sense, man makes history; microprocessors do not" (Rayner 1988).

Rayner's critical remarks about the different nature of mechanical transmitters from human and organizational signal processing stations are well-taken and certainly valid. We agree that a modification of the metaphor of amplification is certainly necessary; but we reject Rayner's conclusion that the metaphor is therefore poor and should not be used for unifying the subjectivist paradigms for explaining risk behavior. First, the inclusion of auto-reflective reasoning of signal processing stations does not change the structure of the model, rather it adds another element into the signal transformation process. The reception of information changes not only the information flow, but also the transmitter's and receiver's internal structure. Using signals as the basic unit of analysis does not imply that stations of signal processing are passive and mechanical transformation stations. Changes of stations, be they mental, organizational, or behavioral, are neither random nor arbitrary, they are reflections on information received and processed. Without communication, there is no change.

Second, institutional transmitters do change over time, but typically over 
long periods of time. They remain fairly stable and constant and resist internal change by institutionalizing binding rules for continuing their assumed service of signal transformation. To stay in Rayner's terminology, organizations such as the staff of newspapers or television stations do not become second hand car dealers or political agencies even if individual members within these organizations decide to do so (they may drop out, but as a rule cannot change the organization). The relative stability and predictability of the selection and amplification rules of organizations dealing with signal transmission are the prerequisites for studying cause-effect relationships in social systems. The model of amplification may indeed be limited for historical analysis, but makes sense as a conceptual model for sociological studies about communication.

The components of messages. The amplification mechanisms of signals are based on formal criteria such as quantity and placement. Although these formal criteria are already powerful agents of amplification, the style and composition of messages are additional content-related amplification mechanisms that are frequently employed in coding or re-coding messages.

Messages can be coded in written or oral format. Oral presentations encompass verbal and nonverbal information. Nonverbal information is conveyed through gestures, appearance and situational context. Receivers or transmitters may also have images about the information source in written communication, but these are either based on prior experience or verbal signals in the message. Verbal and nonverbal communication may reinforce the message if both are in accordance with each other, or attenuate or even contradict the message if in mismatch. A famous example is the TV announcement by then Secretary of State Alexander Haig after the assassination attempt on President Reagan. Sweating with a crack in his voice, he uttered the words, "I am in control here." The mismatch between verbal and nonverbal message was so obvious that hardly anyone was convinced that he was ahead of the situation (Time Magazine, January 18, 1988, p. 23).

The effects of message composition on the receiver have been popular topics in attitude change research (McGuire 1985; Lee 1986, p. 152). A summary of psychological and sociological studies on the effectiveness of messages can be found in Chapter 9. For our discussion on social amplification, we are more interested in the logical components of the message and their amplification potential. Messages may contain factual, inferential, value-related and symbolic meanings (Lasswell 1948; Hovland 1948). The factual information refers to the content of the message (e.g. the emission of an air pollutant is X mg per day) as well as the source of the message (e.g. EPA conducted the measurement). The inferential message refers to the conclusions that can be drawn from the presented evidence (e.g. the emission poses a serious health threat). 
These conclusions may undergo evaluation according to specific criteria (e.g. emission violates federal standards or leads to severe inequities in risk bearing). In addition, cultural symbols may be attached to the message. Symbols are substitutes for chains of associations that evoke images about a relationship between different objects or an object and an attribute. They reduce randomness and complexity of communication within a cultural or subcultural context. Examples of cultural symbols are "big business", "the military-industrial complex", "high technology", and "waste dump".

Communication studies have revealed that symbols present in messages are key factors in triggering attention of potential receivers and in shaping the decoding process (Hovland 1948, p. 371; Kasperson et al. 1988). If, for example, the information source is described as a group of Nobel laureates, the content of the message may well command public attention. Messages from such sources may successfully pass through the selection filters of the transmitters and receivers and be viewed as credible. A press release by the nuclear industry, by contrast, may command much less credibility unless other aspects of the message compensate for doubts about the impartiality of the source.

Sources or transmitters can amplify the different components of the message by taking advantage of the mechanisms of signal amplification. A factual statement repeated several times, especially by different sources, tends to elicit greater belief in the accuracy of the information (volume effect). An elaborate description of the inference process may distract attention from the accuracy of the underlying assumptions (filtering effect). Reference to a highly appreciated and commonly shared social values may increase the receiver's tolerance for weak evidence (muting effect). Adding or deleting symbols is probably the most powerful means to amplify or attenuate the original message.

Assume an industrial spokesperson provides the information that a specific chemical substance has been leaking from a waste repository for two years. One journalist may comment this incident by using phrases such as "leak in waste disposal of a high-tech-park" or "state of the art technology for monitoring emissions", while another journalist may describe the same incident by using phrases such as "air pollution by toxic waste dump" and "poisoning the air we breath and the water we drink".

The analysis of signals and messages with respect to signal amplifiers and message components is one powerful element of tracing the effects of communication. But messages have a meaning for the receiver only within a sociocultural context. Sources and signals are not independent entities but are perceived as a unit by the receiver who links the signal to the sources or transmitters and draws inferences about the relationship between the two. 
That is why the analysis of social amplification cannot be confined to the study of messages, but needs to include the sources, transmitters, receivers and channels of communication.

The sources of messages. The first stage of communication is the framing of a message by an information source. As pointed out earlier, information sources engage in organized communication activities as a means to meet goals or objectives. In accordance with our three-level analysis, sources may be individuals, social groups, or political institutions. Individual sources are rare in risk communication, unless they are eyewitnesses of risk events or directly affected by a cause of risk. Their experiences form the basis on which they compose the messages. These messages are addressed to social groups (request for support), agencies (request for intervention) or fellow citizens (request for solidarity). Unless one or more of these requests receive public attention and evokes an activity by an agency or a social group, the communication effort will slowly diffuse and no amplification effect will occur. As Peters has pointed out, topics can only be brought and sustained on the public agenda if the mass media report about the topic and a social institution or group adopts the topic as part of its own agenda (Peters 1986, p. 9).

Indoor radon is a good example of this mechanism. In spite of good relationships with the national press, Joel Nobel, a physician of Philadelphia, who detected a concentration of $55 \mathrm{pCi} /$ (nearly 14 times the benchmark of $4 \mathrm{pCi} /$ often regarded as "safe" level) in his private home in 1981, was unable to gain more than cursory attention of public institutions and the press because he could not interest an agency or social group to share his concern (Mazur 1987, p. 89). Not before the State of Pennsylvania, alarmed by another even more dramatic case in 1985 , acknowledged the problem and initiated a state-wide survey program, did the national press cover the topic in length and triggered more attention of federal agencies, such as EPA (Mazur 1987, p. 90; Fisher 1987, pp. 27-28).

The lesson for social amplification is that individuals may initiate a communication process that will eventually lead to secondary effects, but that social groups and agencies are the major actors in pushing the topic on the public agenda. The transmitters, in particular the mass media, reinforce this process (agenda persistence) or take up the cause of individuals into the political arena. As a result social groups or institutions are forced to deal with the subject (agenda setting function). So individual action, media interest, and public agency response are all necessary to fuel the amplification process.

The receiver of information. In accordance with our differentiation between micro-, meso-, and macro-level, receivers of information can be classified as 
individuals, groups, or institutions. It is obvious that social groups or institutions can only receive information via reception by individuals working in those social aggregates. But individuals in groups and institutions do not act or react predominantly in their role as private persons, but rather according to the role specification associated with their position. Amplification during reception may therefore differ between individuals in their role as private citizens and in their role as employees or members of social groups and public institutions.

If we turn first to individual receivers as private citizens, we may analytically divide the reception process in seven steps (in reality those steps are integrated). The seven steps are described in Table 13.2. The seven step process of receiving signals and transforming them into beliefs is an analytical model of

Table 13.2. The seven steps of individual reception of information.

\begin{tabular}{|c|c|}
\hline Steps & Description \\
\hline Passing of attention filters & $\begin{array}{l}\text { to select and further process signals from the environment or } \\
\text { social actors }\end{array}$ \\
\hline Decoding of signals & $\begin{array}{l}\text { to decipher the meaning of the signals (investigating factual } \\
\text { content, sources of information, explicit or implicit inferences, } \\
\text { value statements, overt and hidden intentions of information } \\
\text { sources and transmitters, and cues to assign credibility to } \\
\text { information and information source) }\end{array}$ \\
\hline $\begin{array}{l}\text { Drawing one's own } \\
\text { inferences }\end{array}$ & $\begin{array}{l}\text { to come to conclusions about the perceived intentions of the } \\
\text { source and the transmitter, to employ intuitive heuristics } \\
\text { (common sense reasoning) for generalizing the information } \\
\text { recieved and to use symbolic cues for judging the seriousness of } \\
\text { the information }\end{array}$ \\
\hline $\begin{array}{l}\text { Comparing the decoded } \\
\text { messages with other } \\
\text { messages }\end{array}$ & $\begin{array}{l}\text { to analyze the meaning of the message in the light of related } \\
\text { messages from other sources or previous experience }\end{array}$ \\
\hline Evaluating messages & $\begin{array}{l}\text { to rate the importance, persuasiveness and potential for } \\
\text { personal involvement on the basis of the perceived accuracy of } \\
\text { the message, the potential effect on one's personal life, the } \\
\text { perceived consistency with existing beliefs (to avoid cognitive } \\
\text { dissonance), reference group judgments (to avoid social } \\
\text { alienation), and personal value commitments }\end{array}$ \\
\hline Forming specific beliefs & $\begin{array}{l}\text { to generate or change beliefs about the subject of the message } \\
\text { or to reasuure previously held beliefs }\end{array}$ \\
\hline $\begin{array}{l}\text { Propensive to take } \\
\text { corresponding actions }\end{array}$ & $\begin{array}{l}\text { to generate intentions for future actions that are in accordance } \\
\text { with the newly formed beliefs. }\end{array}$ \\
\hline
\end{tabular}


the cognitive procedure by which individuals articulate an opinion and gradually form an enduring attitude (see Fig. 13.2). Similar, though more simplistic, models of information reception have been used to analyze and compose emergency messages. Sorensen and Mileti distinguish between "hear, understand, believe, personalize, and respond" (Sorensen and Mileti, this volume). We have further substructured the categories of believing and personalizing, but the basic sequence is similar. This cognitive process has to be supplemented further by emotional and subconscious processes that filter incoming messages and co-determine their evaluation (Lee 1986, p. 156; Renn 1984, pp. 111-115).

The decoding and evaluation process determines the selection of information that the receiver regards as significant. The components of the decoded message that are inconsistent with previous beliefs or contradict values to which the receiver feels attracted, are ignored or attenuated. The signals are intensified if the opposite is true.

In principle, the same process takes place in individuals in their roles as members or employees of social groups or institutions. But the decoding process of signals is co-determined by the following factors:

1. professional standards and rules (characteristic for scientific communities, interest groups, media editors, political institutions, etc.);

2. institutional interests, functions, and foci;

3. rules and role expectations pertaining to the specific position of the receiver;

4. interpretation of those role expectations by the holder of the position.

The role-specific reception factors are internalized and reinforced through education and training, identification with the goals and functions of the respective institution, belief in the importance and justification of the produced output, and positive rewards (promotion, salary increase, symbolic honors) and negative punishments (downgrading, salary cuts, disgracing). Occasionally, conflicts between personal convictions and institutional obligations evoke psychological stress which may further lead to segregation from the institution. Receiving information that challenges one's own ties with the institution may trigger such a reaction. If this reaction is communicated back to the source or other transmitters, public attention is almost certain. The spectacular changes of camps by nuclear engineers who left the nuclear industry and joint the anti-nuclear movement were highly amplified in the public arena and contributed to the negative image of the nuclear industry in the public. It is interesting to note that the reverse process, a change from the anti-nuclear activist group to a pro-nuclear camp, has either not occurred or has been attenuated in the communication process. 
Role and functions of the transmitter. The transmitter has two roles in the communication process: first, transmitters receive information from sources and process this information similar to the final receiver. But in addition to personal selection filters and evaluation strategies, professional and institutional rules govern the selection of received signals and their interpretation. Journalists, for example, follow specific professional guidelines such as hearing both sides in a controversy, as well as institutional rules such as the required editorial style and the expectations of the perceived target audience of the respective medium.

Second, the transmitter acts as an information source by sending signals to the final receiver. The re-coding of messages involves conscious or unconscious changes of the original information material. Messages from several sources may be integrated into one new message or comments may be added. Obviously, both processes take place simultaneously, i.e understanding and re-coding the incoming message is an integral part of the transmitting process.

The transformation process of messages during transmission has been a popular topic of communication research. From a theoretical point of view, eight basic concepts about the nature of this transformation have been suggested in the literature (Sood et al. 1987, p. 30; Peters 1980; Shoemaker 1987, p. 125; Peltu 1985, pp. 129-130; Lee 1986, p. 175):

1. The mirror hypothesis (media reflect the occurrences of the real world). According to this view, the media behave like true hifi- amplifiers; they transport the original message from the source to the final receivers without distortion or change. Even the selection of the news is done in accordance with the perceived social allocation of importance to different events.

2. The power hypothesis (media reflect the commercial and political pressures of advertisers and interest groups in society). According to this view, the centers of power are provided with sufficient means to manipulate the selection and amplification process of information. Although journalists may act under the illusion of freedom of information, subtle pressures and incentives from major economic and political forces lead to the adoption of messages that support the legitimacy of the power centers.

3. The agenda setting hypothesis (media reflect occurrences and opinions in the real world, but act as selectors and amplifiers for such events and issues). According to this view, the media act as promoters for special issues and force the political system to deal with these issues. The selection and amplification process, however, is not arbitrary or at the discretion of the media professionals. Rather journalists select and intensify signals that are generated by major social groups or that they anticipate would trigger attention or concern of such groups. 
4. The issue creation hypothesis (media are free in creating and sustaining issues of public concern). According to this view, media are powerful actors in society and unrestricted in their pursuit of selecting and amplifying signals. Professional standards or common values of the cultural elite to which the media professionals belong create a degree of homogeneity among the media; but political commitments and different lifestyles evoke at the same time a high degree of diversity among the media. Therefore, it is rather difficult to predict the aggregate effect of the media coverage on the political and social system.

5. The gate-keeping hypothesis (media act as information selection agencies and as a forum for inter-group communication). According to this view, the media have an important filtering function to select and amplify signals out of an abundance of information available. The selection process is widely governed by professional standards, which assure a rule-oriented and to a specific extent predictable procedure. Social groups use the media often to test whether their claims for more social resources (such as money, power, prestige, and others) pass the attention filters of the media. If so, they may sense a readiness of society to take such a claim seriously.

6. The mediating hypothesis (media act as mediators and catalysts of social conflicts). According to this view, the media play an active role in transporting social claims or positions from one social group to another. These groups are often unwilling to communicate directly with each other and use the media as an intermediary or even arbiter in the process of conflict resolution.

7. The social construction hypothesis (media reflect the social constructions of reality held by the news personnel). According to this view, the media select issues that social groups or individual actors in society deem important. The degree of relevance is a function of the magnitude of social perception. The more social groups deal with an issue or demonstrate conflicting views on this issue, the more such an issue becomes a topic of media coverage.

8. The symbolic interactionist perspective (media share common meaning with the cultural group to which they want to communicate). According to this view, the media serve specific cultural constituencies and assist in developing a sense of identity and community among the members of such a constituency. Depending on the values and beliefs of the respective constituency, the media serving this constituency will select and amplify signals that strengthen and confirm these beliefs and values and ignore signals that could jeopardize them.

These eight approaches are not exclusive. Agenda setting and gate keeping are 
probably complimentary as are social construction and symbolic interactionism. The basic differences between the approaches may be confined to two major dimensions: First, are the media creating new messages or are they reflecting existing messages and second, how biased are news-media in their coverage vis-a-vis culturally internalized values and socially externalized pressures? Both questions have not found a final answer yet (Peltu 1985, pp. 140-141; Mazur 1987, p. 86; Lichtenberg and MacLean 1989, pp. 33-48).

With respect to the first question, the literature suggested a strong influence of the media on public opinion in the early years of communication research. Through extensive testing, however, this hypothesis was later substituted by the agenda-setting hypothesis. More recently, a renaissance of the issuecreation hypothesis has occurred but with a stronger emphasis on long-term, mainly unintentional issue creation mechanisms by massive and diffused media consumption (Peltu 1985, p. 140). With the rise of cultural theories of risk, the interactionist view has also gained more popularity, particularly in the United States.

With respect to the second question evidence has been gathered to support almost all possible viewpoints. Political and commercial pressures have been detected in media coverage as well as courageous news reports in conflict with all vested interests. Cultural biases within the journalistic community have been found, but also a variety of different political and social attitudes among journalists. Some journalists perceive their job as a mere translation of events into signals while other believe they should play a more active role in shaping and explaining the issue (cf. the controversy about the studies of Kepplinger in the review by Lichtenberg and MacLean 1989, pp. 37-45).

In short: the extremes that media are mere reflectors of reality or that they are docile instruments of social pressure groups may occasionally be true, but are not the rule. In reality, the situation is more complex: Media coverage is neither dependent on external pressures nor an autonomous subsystem within society (Lowry and DeFleur 1983; Raymond 1985). It reflects internalized individual values, organizational rules and external expectations. It depends on the issue itself, the institutional context and the political salience of the issue which of the three factors is likely to dominate the signal transformation process. A universal theory of how this transformation takes place is therefore not likely to evolve (Peters 1980, p. 13).

The concept of social amplification, however, provides a framework that is wide enough to accommodate this complexity of signal transformation through the media. Due to its focus on signals and not on motivations, intended and unintended changes of the messages are equally covered. Subjective intentions and objective effects may be compared by studying the original intentions, the composition of signals capturing these intentions, the 
understanding of the messages by transmitters and receivers, and the effect of re-coding these messages on attitude formation and behavior. The concept does not contain a hypothesis about the selection and amplification rules (since these are probably context related), but implies operational strategies for further empirical research about specific rules of amplification within different institutional and topical contexts.

Transmitters are, of course, not only media. Social groups and institutions frequently serve as transmitters of information, in particular if they want to be sure that their message will reach the receiver unchanged. In the past channels for non-media transmitters were restricted to advertisement and direct mailing. In addition, representatives of institutions and social opinion leaders are often subjects of interviews or TV talk shows and thus potential transmitters of messages of their own institution or their reference group to the public. Many interest groups publish journals or newsletters to keep their members informed. With the evolution of new electronic information technologies, the restricted scope of reaching a mass audience directly from the information source has been broadened. Organizations may now operate cable TV stations, feed their information into video-text systems or offer data banks or computerized information systems to their targeted customers.

The channels of communication. The selection of channels is usually a decision of the information source, but channels may change during transmission. A press release by an agency may be converted into a brief television spot; a video by an environmental group may be discussed in a journal or newspaper; an interview during a news broadcast may become headlines of the newspapers. Each channel has different means of amplification: visual symbols and images are powerful agents of attenuation or intensification in journals and TV; gestures and appearance are important signal amplifiers in oral presentations; verbal symbols have a strong effect in written manuscripts. The investigation of social amplification has to account for these different mechanisms of amplification with respect to channel differences.

Channels are not clearly defined in most communication studies. The function of channels is to transmit signals from a source to a receiver. The popular classification of channels in oral, printed, broadcast (radio) and televised messages may be helpful to identify mechanisms of amplification which are unique for each of these message types (see Lee 1986, p. 150), but these types refer to the media through which the messages are channelled, but not to the channels themselves. We therefore prefer a taxonomy of channels according to the distance between source and receiver and the way this distance is bridged. According to this concept, we can distinguish six different channel types: 
a. personal face-to-face interaction (conversation, informal meeting);

b. group face-to-face interaction (lectures, formal meetings, etc.);

c. personal indirect interaction (letters, home videos, telephone, etc.);

d. group indirect interaction (video conference, telephone conference, etc.);

e. target audience indirect interaction (brochures, special journals, video clubs, information services, data banks, etc.);

f. diffuse audience indirect interaction (mass media, TV, radio, newspapers, books, paintings, etc.).

The two classification parameters are size of audience and physical presence of communicator(s). The size of audience corresponds with our previous scheme of micro-, meso-, and macro-level. The structuring of amplification patterns according to the sequential stations of communication provides an analytical framework on which we can now specify the special conditions for communicating risk.

\section{Social amplification in risk communication}

The organizational structure of risk communication: In which way does the theory of signal amplification apply to risk communication? Figure 13.3 depicts the major actors of risk communication as part of the classical communication model. Sources for risk-related information are basically scientists or scientific institutions, public agencies, such as EPA or FDA, interest groups such as industries or environmentalists, and in the case of hazardous events (physical changes caused by hazardous activities) eyewitnesses. Theses primary sources code information in form of reports, press releases, or personal interviews and send them to transmitters or occasionally directly to the final receivers.

The second step of communication is the coding and re-coding procedure at the transmitting stations. The media, other public institutions, interest groups, and opinion leaders are potential transmitters for risk-related information. A press release from EPA may stimulate industry to hold a press conference or to write an open letter to the agency. Interaction among social groups, in particular among adversaries, often takes place through the media and not through direct communication. The goal is to mobilize public support and to initiate public pressure. Peters lists three reasons why social groups like to use the media as a platform for their risk communication efforts (Peters 1986, pp. 3-4):

1. The communication is pubic. This makes it hard for the addressed group not to react. 


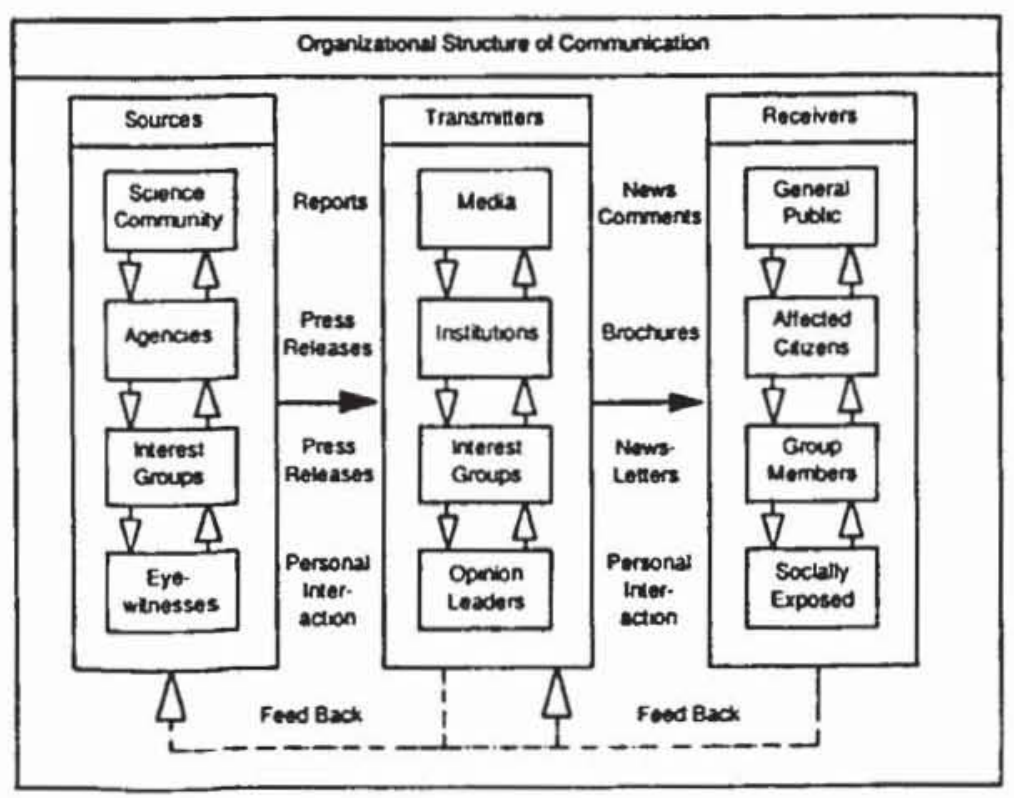

Fig. 13.3. Organizational structure of communication. In risk communication one can identify the major actors in each step of the communication process. Primary sources are usually related to scientific communities or agencies; secondary sources are political institutions and interest groups. Both organizational types of sources may compete with eyewitnesses of hazardous events. The transmitters are dominated by the mass media, but also groups in society act frequently as information brokers. The receivers of information are substructured in the general public, usually the target of mass media, affected citizens, members of social groups, and socially exposed individuals. The effect of the message depends on the targeted audience and its special amplification mechanisms in receiving and processing information.

2. The communicated information gains additional importance since it has passed the selection filters of the media.

3. The public communication effort may trigger support by other groups or more general public opinion pressure, in particular if the information contains references to widely appreciated social goals and values.

The communication process among sources or between sources and different transmitters is like staging a play with the general public as audience or sometimes as referees. The more applause each group of actors receives, the more they will be inclined to ask the producer for more resources, usually on the expenses of others. If for example the environmentalists gained enough social support for their messages, they would exert pressure on the administration or political institutions to meet their claims. These claims may contain a transfer of money from industry to pollution control. Thus industry will be equally eager to influence public opinion in order to prevent this transfer of resources. Gaining public support and influencing public opinion may not be the only factor by which resources are distributed among groups for different 
purposes, but in democratic, in particular adversarially structured, societies it is one of the most influential ones. Thus, communication between the key actors is likely to occur in front of the public because this increases the chance (but also the risk) of gaining (or losing) additional momentum through public support.

The last step is the processing of the re-coded messages at the receiver. Again, it is helpful to distinguish between different types of receivers. The media usually serve the general public, but many journals are targeted to specific audiences within the general public. Specialized journals are either appealing to professional standards (science communities, business circles, risk assessors), avocational activities (culture, sports, travelling etc), or value groups (environmentalists, religious groups, political camps etc). The information will be framed for each audience in a different manner to assure their attention and to please their expectations. It would be interesting to investigate the signal composition and transformation process undertaken for these different target audiences with respect to an identical event.

In addition, citizens affected by a risk source may process the information differently from the vast majority of non-affected persons. They may use incoming information to mobilize political responses which will lead to further media coverage. The reports about the responses may eventually mobilize the non-affected public. Public support reinforces the political responses again. The dynamics of isolated actions, media interest, and gaining public support is specifically interesting for risk communication because the risk concept implies the notion of statistical losses rather than individual victims. Public pressure on risk-related topics is dependent on a small group of persons at high risk who take up the issue and use their ability to mobilize the public. Mobilization is usually successful if members of the public feel sufficient emotional affection to identify themselves with the potential victims or if they can be convinced that they or their descendants are likely to become the next victims. Love Canal may be a good example for the mechanism of identification, saccharin for the mechanism of potential victimization.

The primary sources of risk communication. Nature and technology are both sources for hazardous events, such as earthquakes, fires, explosions, pollution or radiation. Scientific analysis attempts to determine the physical impact of such events or to hypothesize about the magnitude and the probability of potential impacts for extremely rare events for which statistical data is not (yet) available. Observation and analysis of actual events and simulation of potential events lead to an estimate of the magnitude of the impacts, the probability of their occurrence, and the distribution of these impacts over time, space, and population subgroups. These estimates can only be coded in 


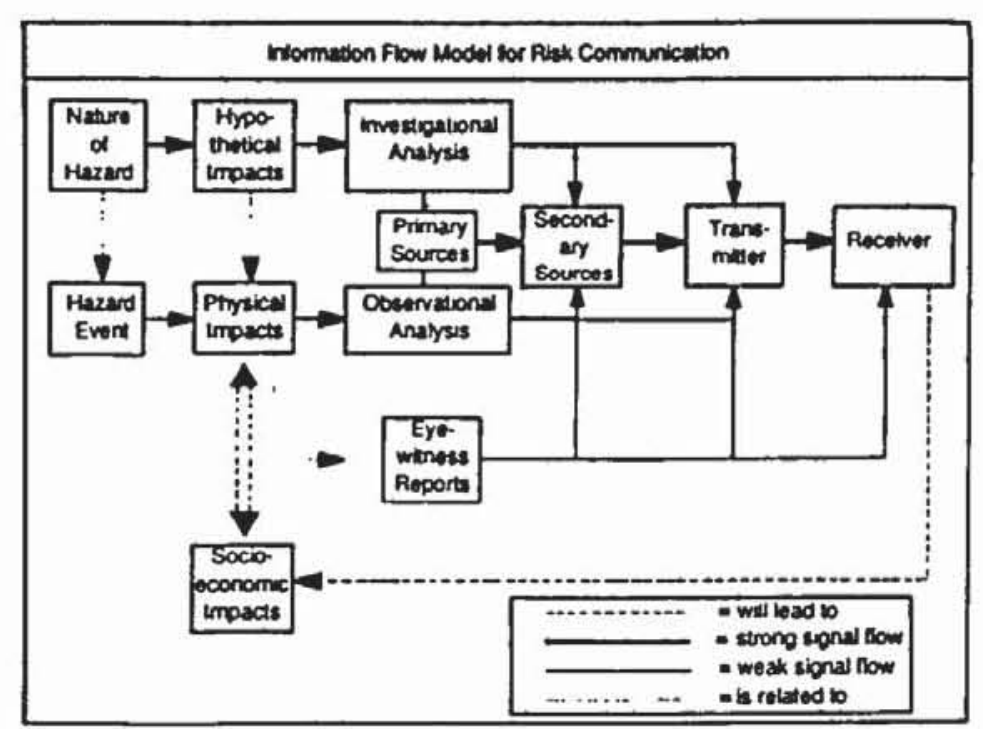

Fig. 13.4. Information flow model for risk communication. Primary sources for risk communication are scientific communities and eyewitnesses in the case of hazardous events. Through observational analysis of actual impacts of past hazardous events or through simulation of such impacts for potential hazardous events, scientists select a special set of signals, amplify them, and code them into communicative signals. Eyewitnesses are also selecting signals, but operate under a different selection rule. While scientists focus on the typical and general aspects of a hazardous event, eyewitnesses focus on the uniqueness of the situation and the concrete sufferings experienced in a tragedy. Secondary sources, such as agencies or social interest groups function as a secondary amplification station by selecting and intensifying those signals that shed positive light on their own performance or help them to find public support and to gain social resources. At this stage the selection process has inevitably produced controversial messages which will be picked up together with the eyewitnesses' reports by professional transmitters who will make the controversy itself the main subject of their message. Thus the receiver will be confronted with information emphasizing conflict, dissent, interest driven interpretation, and controversy.

form of signals, i.e. in scientific reports or studies. Figure 13.4 is an attempt to illustrate this process using the major stations of the communication model.

The selection of what types of signals are collected from the physical event or the hypothetical simulation of this event involves individual or group judgments about relative importance. To restrict one's attention to probabilities and magnitude reflects the strategy of abstracting typical and universal characteristics from a unique event as a means for comparing this event with other similar events or designing measures for reducing the risk of future similar events. Scientific risk assessment is motivated by the purpose to provide information about the relative potential of hazardous events to produce adverse effects based on past experience. The subjective nature of such assessments have already been discussed in the first chapter, here we are only interested in the signal selection process. Events, such as earthquakes or chemical spills, are scanned for signals that are valuable to construct probabil- 
ity distributions of adverse effects. Other signals about human sufferings, responsibility for the disaster, inequities in the experience of risk, and political implications are deliberately excluded from the signal collection process.

As Johnson has discussed in detail (Johnson 1988), this selection rule may benefit special political interests more than others; but the rule is abstract, universal, and a part of a whole set of scientific conventions on which scientific communities have agreed regardless which cause of risk is considered. A recent comparison about risk perception of nuclear energy versus Aids revealed the interesting finding that the same scientific rules of risk assessment appealed more to the pro-nuclear community in the case of nuclear energy and more to the left, usually anti-nuclear, group in the case of AIDS and vice versa (Wiedemann, personal communication).

Thus the universalism of science (Merton) - one of the four major scientific principles - prevents a consistent bias towards one political interest even if the applied scientific method relies on subjective judgments and conventions. It may benefit industrial interests in the case of rare, catastrophic risks and harm them in the case of diffuse, routine risks exposing larger populations.

This has several consequences for risk communication: First, risk analyses may contain surprises for the agency conducting or ordering it. Such surprises may easily lead to conflicts between primary and secondary information sources about the meaning and importance of the respective study. Second, attacking risk analysis as a method may be counter-productive for many social groups as the application of this method may provide supporting arguments for the groups' claims in the future. Some environmental groups made this experience after acknowledging that the condemnation of risk analysis in the nuclear case did not help them fighting against the use of pesticides where risk studies partially supported their claims. Third, as the results of risk analysis are not eo ipso predictable, social pressure by interest groups builds up to supplement or modify the rules of assessment in order to gain a more "desired" outcome. All three processes produce dissonant communication signals sent from one group to another or directed to a broader audience. The tensions among those primary and secondary sources are themselves issues of risk communication and usually more popular in public media than the actual results of the risk assessments.

A second pathway of conflictual or parallel signal selection and transformation is the experiences of eyewitnesses or affected persons. These individuals produce anecdotal evidence of the hazardous event which is coded in communication signals and conveyed to other individuals or transmitters. Anecdotal evidence competes with the systematic and abstract evidence provided by scientists. It should be noted that the impacts (even the hypothetical ones) are real or potential physical phenomena, whereas the information 
about them are reflections of different social groups (scientists and eyewitnesses, for example) that are governed by personal impressions (eyewitnesses) or professional conventions (equal weight for probability and magnitude in risk equations, for example).

Primary sources therefore collect and select signals from the physical world, re-code them into verbal signals and assign them different degrees of significance and often symbolic value. Special properties of the risk situation may cause specific attention, while others may easily be overlooked. Scientific conventions focus on specific aspects of risk. They help to identify the typical elements of all covered risk situations, but may obscure the uniqueness of the specific event or hazard under consideration. Likewise, anecdotal evidence seems to center on the uniqueness of the situation and the specific circumstances of the event and to neglect the typical patterns that characterize risk in general. One major problem of risk communication is therefore the integration of scientific and anecdotal evidence, a problem which is aggravated by the stochastic nature of risk.

The secondary sources of risk communication. Secondary sources are either scientific institutions, management agencies, or interest groups. They pick up the information, which is frequently collected by in-house members or at least sponsored by the institution. Scientific investigations focusing on dose-effect relationships and probabilities of adverse events will be the prime material for the formulation of the risk message. Eyewitness reports may also be included, but will probably get less attention as institutions want to concentrate on the general message of the respective incident just like the scientific community.

The main objectives of the concerned institutions are to forecast, analyze, or manage the hazard. They want to draw generally applicable conclusions from the events or studies. This is also likely to be the subject of their risk communication. Often, however, are transmitters and the public more interested in the specific circumstances of the one incident reported or the consequences of a single hazard event. The intention of the source to communicate the common lessons and to put the risk in perspective conflicts with the interest of the receiver to learn more about the incidence and the real or potential victims.

Furthermore, each source will likely collect and pass on information that relates to the designated service of the institution and that also provides good arguments to legitimize its existence and performance as well as its share of social resources (money, prestige, and power). A variety of secondary sources with different interests and purposes compete for these resources. Thus they will differ in the selection and processing of signals stemming from primary sources. This difference in interpretation may be aggravated by different 
competing risk assessments which reflect adversarial science camps or result from scientific advocacies within interest groups. But even if all these sources relied on the same primary sources or cited the same evidence, the messages would still look like they were drawn from completely unrelated data bases.

Industry, regulators, scientists and environmental watchdogs focus on different aspects of the problem and amplify signals that each of them regards as confirmation of their basic philosophy and that emphasize their role and function in the assessment and management of the respective risk. Although not necessarily so, the difference in messages is usually not a product of misinformation, manipulation, or even lying. Every communicator has a different perspective in perceiving and evaluating the issue and is interested in conveying that perspective to the outside world. Fragmentation of information is therefore an inevitable side effect of plural interest articulation. The process of signal reception and re-coding in this stage is less related to the properties of the hazard, although this information may be packaged within the message, but rather to the efforts of the institution to assess, analyze or manage the respective risk.

The transmitters of risk-related information. The third stage of communication deals with the professional transmitters, i.e. the information brokers and the media. They function as primary transmitters of information between the eyewitnesses and primary and secondary sources on one, and different groups of the general public on the other side. The media collect information from direct eyewitnesses of hazard events (anecdotal evidence). They have usually access to the primary scientific reports (scientific evidence), but may prefer to use its popular derivations (such as articles in popular science journals). They will be bombarded with press releases and other information from managing institutions or socially relevant groups. This abundance of material has to be collected, selected, digested, and finally re-coded.

The diversity of different perspectives on the nature of the risk and its best management approach will be one of the major issues carried on by the transmitters, in particular those serving the general public. The widely accepted rule of fairness in news coverage demands equal treatment for all points of views. While conflict resolution rests on "true" evidence in science communities, and on the majority vote in democratic decision making, conflicts are usually not reconciled in the media; rather the different sides are merely presented regardless how much scientific evidence they are able to present and how many adherents they are able to collect. Transmitters in a pluralistic society tend to reinforce diversity, dissent and relativity of values (Rubin 1987, p. 53). Even specialized journals tend to focus on controversies as long as they 
fit into their general philosophy. Thus dissent and ambiguity are inevitable and irreversible parts of risk information in addition to the uncertainty of the consequences.

Other issues apart from the received messages are events that have been covered up, management failures that were not reported, internal disputes inside of agencies, hidden agendas and other information that was either withheld or simply overlooked by the primary or secondary sources. Reports about such organizational failures challenge not only the credibility of the initial message, but destroys the reputation and credibility of the information source. Most institutions have difficulties walking on the ridge between selfinterest and fear of investigative revelations. Honesty and functionality are often conflicting goals (Kasperson 1987b).

The nature and the magnitude of the original hazard is not the major point of interest for most transmitters, rather the way institutions handle risks and communicate about their activities. Empirical studies demonstrate that neither the number of victims in an event nor the expected fatalities as a result of risk studies are correlated with the volume and intensity of media coverage (Singer and Endremy 1987, p. 14; Wilkins and Patterson 1987, p. 84; Adams 1986, p. 113; Sood et al. 1987, pp. 36-37).

As Singer and Endremy point out, the media emphasize hazards that are relatively serious and relatively rare; it is the combination that gives them their punch (Singer and Endremy 1987, p. 13). For example, the Chernobyl accident with 31 acute deaths cases received 129 minutes of CBS News coverage while the 1976 Tandshan earthquake leaving 800,000 people dead received less than 9 minutes on the average TV evening news (Sood et al. 1987, p. 37).

The literature contains endless lists of factors that are assumed to determine the attractiveness of risk-related signals for transmitters. Such factors include: technologically induced hazard (versus natural hazard), possibility to blame someone for the outcome (Sandmann et al. 1987, p. 105), cultural distance from the place of occurrence (Adams 1986), human interest component, drama and conflict, exclusiveness of coverage (Peltu 1985, pp. 137-138), proximity to politically hot issues, prestige of information source, and degree of conflict among stakeholders (Peters 1980).

Reviewing the abundance of theoretical suggestions and partially confirmed empirical results, one may come to the conclusion that the signal amplification process in the media is almost random or at least void of any systematic pattern. But some insights have been gained as a result of the media studies undertaken so far. The major components of risk studies, probabilities and magnitudes, seem to play only a minor role in the media coverage; they are hence attenuated. Intensified, however, are signals relating to conflicts among 
social groups, contradictions between primary and secondary sources of information, risk events that could have been prevented or mitigated, and the involvement of individuals or organizations with high prestige and political influence.

Further studies about the communication process itself, the selection and amplification criteria in media, role expectations of journalists and final receivers are therefore necessary for gaining more insights into the stage of transmitting risk-related information and shedding some more light on the crucial role transmitters play in re-coding and articulating messages (cf. Peltu 1985; Friedman et al. 1987; Wilkins and Patterson 1987).

The receiver of risk information. The final stage comprises the reception of the message by the receiver, a member of the public or other target audience. Again, receivers are overwhelmed with information of which they can only digest a small fraction. Since information brokers and the media depend on getting the attention of the receiver, they have to send out signals that they anticipate will be absorbed by the receiver. The common phrase "Bad news are good news" is a reflection on the anticipated interest of the consumer of messages. The receivers then decode the signals and amplify the ones that contain significant information in their view.

Significance is achieved through cultural and social symbols incorporated into the message and personal appeal, a product of social fashion, personal values, related attitudes, and peer group influences. In addition to the messages received through the media, the receiver can rely on his or her own experience (or imagination), common sense, and direct interaction with members of peer groups. The final beliefs that are formed reflect an amalgamation of these different sources. In this stage alleged or real properties of the hazard, perceptions of institutional performance, the conveyed image of transmitters and other interested parties, and personal preferences are the basic elements for the formation of an opinion and later an attitude (Lee 1986).

The formation and articulation of attitudes generate a propensity to take actions. As known from many attitude studies, the willingness to take actions is only partly related to overt behavior (Allport 1935; Rokeach 1978; Fishbein and Ajizen 1981; Wicker 1979). A positive or negative attitude is a necessary, but not sufficient step for corresponding behavior. A person's decision to take action depends on many variables other than attitude, such as behavioral norms, values, and situational variables. Research on attitudes is often capable of explaining why specific reactions by individuals or groups have occurred, but it is less successful in predicting responses on the basis of known attitudes. In addition, laboratory studies on attitude change may be weak 
predictors of real behavior or even behavioral intentions, as many studies have shown (Wicker 1979; Meinefeld 1978; Rokeach 1979; McGuire 1985; Lee 1986).

Similarly, the communication process will influence the receiver's behavior, but due to the multitude of sources, the plurality of transmitters, and the presence of situational forces on personal behavior, the effect of a single communication activity is almost impossible to measure, not to mention to predict. Studies about risk perception, technology attitudes, symbolic associations with specific risk sources, and communication research itself are prime sources for explaining attitudinal and behavioral changes resulting from risk communication.

For the investigation of the amplification effects in individuals, more studies on attitude change and behavior in relation with risk information should be conducted. Substantial evidence has been collected for disaster warning and the effect of emergency communication (Sorensen and Mileti, in this volume; Quarantelli 1981; Mileti 1975; Perry et al. 1980). The results of these studies should provide a valuable source of hypotheses for a broader application to study the effects of risk communication on individual receivers.

\section{Secondary and tertiary effects of social amplification}

Behavioral responses. So far we investigated the flow of information from the original hazardous event to the final receiver. Our focus was on the structure and functions of signal selection and amplification occurring during the transmission of information. Also we were interested in the attitudinal or behavioral changes as a result of risk communication.

Changes in attitudes and risk-related behavior are triggers for new rounds of communication, but also causes for social actions and organizational responses. In our terminology, changes in social and institutional behavior that were induced by individual responses to risk communication are called secondary effects of social amplification (Kasperson et al. 1986). Secondary effects therefore evolve as responses to signals sent from the receivers of risk communication (on the micro-, meso-, and macro-level) to risk handling institutions. Secondary impacts include such effects as enduring mental perceptions, personal apathy, political pressure, institutional or political changes, or new social movements.

Secondary impacts are, in turn, perceived by social groups and individuals so that another stage of amplification occurs to produce third-order impacts. Those impacts may influence the relationship between social groups and the political system, evoke novel forms and means of political culture, induce 
legitimation problems for political decisions, and may lead to the emergence of new subcultures. There is certainly a point where such macro level effects cannot be related to risk communication alone, but where the problems of risk communication are one component among others that aggravate or alleviate communication and decision making processes in society.

Secondary effects of communication. In addition to attitudinal and behavioral changes induced by risk communication, the communication process itself may follow specific patterns resulting from the continuous flow of information from sources via transmitters to receivers and vice versa. We label these effects of repeated communication as secondary effects of communication and call the process of pattern creation routinization of information transfer. Routinization is not a function of the social amplification of signals, but a result of social experience with signal transformation in the past and of the standardization of expectations vis-a-vis sources, transmitters and channels. Typical examples are stereotypes about hidden agendas of communicators or alleged characteristics of channels.

Secondary effects of communication are not unrelated to the amplification of signals in each round of communication. We hypothesize that the repetitive use of amplification effects, such as muting or mixing, cause or at least promote the routinization of information transfer. Therefore, it is only logical to include this second order phenomenon in our conceptual framework. Among the many forms of routinization, we would like to mention partisan relationships and stigmas. Partisan relationships lead to polarized views and corresponding information selection; stigmas refer to negative imagery associated with undesirable qualities.

Other forms of routinization may be added. Needleman referred to ritualism in risk communication (1987, p. 20-25) and characterized many communication efforts as attempts to meet formal information requirements without giving any substantial information. Whether the term "ritual" describes this process adequately, may be doubtful; but ritualization constitutes a form of symbolic information exchange not focused on the message, but on the fact or circumstances of information transfer. A major objective will be to identify and refine different mechanisms of routinization and their effects on attitudinal structure and behavioral changes. Furthermore, the conditions and environments in which such higher order communication patterns emerge have to be analyzed and modelled. 


\section{Conclusions: lessons for a theory of risk communication}

Risk communication is a novel concept in the scientific pursuit to understand and analyze risk related decisions and behavior in modern society. But the new term has only changed the focus of attention from a static description of what risk means for different communities to a dynamic analysis on how these communities exchange information about risk and adjust their behavior. The old division lines between objectivistic and subjectivistic approaches, between psychological and cultural understanding of risk behavior, between individualistic versus structuralistic theories of risk perception and management, and idealistic versus materialistic view of the issue prevail in spite of the common interest in communication.

The concept of social amplification of risk provides a framework for the analysis of communication as well as other social activities and constitutes a dynamic model which facilitates the systematic interpretation of empirical data and attempts to integrate the existing perspectives into a higher-order terminological model. The concept will certainly not encompass all perspectives, and it will not be capable of unifying different scientific camps. This is neither a realistic expectation, nor the purpose of our approach.

In the social sciences, diversity of conceptual frameworks and perspectives have expanded our knowledge and contributed to criticizing ideological elements in different competing models. The complexity of social systems, the non-linear relationships among social variables, the indeterminate nature of future human actions, and the occurrence of unforeseeable surprises in history make the concept of a unified social theory an illusion. What we attempt, however, is to create a new framework that allows the inclusion of different concepts and perspectives within a larger integrative context. In this way the perspectives are not exclusive and communication among scientists can be facilitated. Ideally our concept should be used to define new research areas, identify links among different research perspectives, and provide a terminology which allows comparisons of results from varying disciplines and research camps. We want to overcome fragmentation and seek new insights into interrelations, but not impede diversity.

The model is not a theory in the classical sense. It does not contain hypotheses or deductions that could be tested empirically. It provides a conceptual framework to select, order, and classify social phenomena and suggest theoretical relationships among them. Its applicability cannot be tested by empirical analysis, but by its usefulness to deduct empirically testable theories and to offer a perspective to interpret and classify risk communication data. Therefore, the model cannot be falsified through analysis; but it may be rejected because it does not offer a better explanatory framework than any of the 
competing perspectives. If the model of social amplification proves a useful guideline for initiating research that can yield results beyond the scope of the traditional frameworks our major goal would be accomplished.

\section{References}

Adams, W.C. 1986. "Whose Lives Count?: TV Coverage of Natural Disasters," Communication 36, No. 2, 113-122.

Allen, F.W. 1987. "Towards a Holistic Appreciation of Risk: The Challenge for Communicators and Policymakers," Science, Technology, and Human Values 12, Nos. 3 and 4, 138-143.

Allport, G.W. 1935. "Attitudes," Handbook of Social Psychology. Clark University Press: Worcester, MA., pp. 798-844.

Brown, P. 1987. "Popular Epidemiology: Community Response to Toxic Waste-Induced Disease in Woburn, Massachusetts," Science, Technology, and Human Values 12, Nos. 3 and 4, 78-85.

Covello, V.T. 1983. "The Perception of Technological Risks: A Literature Review," Technological Forecasting and Social Change 23: 285-297.

Covello, V.T., P. Slovic and D. von Winterfeldt. 1986. "Risk Communication: A Review of the Literature," Risk Abstracts 3, No. 4, 172-182.

Covello, V.T., P. Slovic and D. von Winterfeldt. 1989. "Disaster and Crisis Communications: Findings and Implications for Research and Policy," in H. Jungermann, R.E. Kasperson and P.M. Wiedemann (eds), Risk Communication. Nuclear Research Center: Jülich, West-Germany, pp. 131-154.

Davies, R. 1987. "The Effectiveness of the Sizewell B Public Inquiry in Facilitating Communication about the Risks of Nuclear Power," Science, Technology, and Human Values 12, Nos. 3 and $4,102-110$.

DeFleur, M.L. 1966. Theories of Mass Communication. New York, NY.

DeFleur, M.L. and S. Ball-Rokeach. 1982. Theories of Mass Communication, 4th edition, Longman: New York.

Fishbein, M. and J. Ajizen. 1975. Belief, Attitude, Intention, and Behavior: An Introduction to Theory and Research. Addison Wesley: Reading, MA.

Fisher, A. 1987. "Risk Communication: Getting Out the Message about Radon," EPA Journal 13, No. 9, 27-29.

Fiskel, J. and V.Y. Covello. 1987. "Knowledge Systems, Expert Systems, and Risk Communication", in: J.L. Mumpower, L.D. Phillips, O. Renn and V.R.R. Uppuluri (eds), Expert Judgment and Expert Systems, Nato ASI Series: Computer and System Sciences, Vol. 35. Springer: Berlin, FRG., pp. 85-103.

Friedman, S.M., C.M. Corney and B.P. Egolf. 1987. "Reporting on Radiation: A Content Analysis of Chernobyl Coverage," Communication 37, No.3, 58-67.

W. Haefele 1974. "Hypotheticality and the New Challenges," Minerva 12, No. 3, 303-322.

Haefele, W., O. Renn and P. Erdmann. (in preparation) "Risiko und Undeutlichkeiten," in: W. Haefele (ed), Horizontal Integrierte Energiesysteme. Jülich, FRG.

Hovland, C. J. 1948. "Social Communication," Proceedings of the American Philosophical Society 92, 371-375.

Jasanoff, S. 1987. "EPA's Regulation of Daminozide: Unscrambling the Messages of Risk," Science, Technology, and Human Values 12, Nos. 3 and 4, 116-124. 
Johnson, B.B. 1988, "Political Interests in Risk Assessment", Manuscript. Science, Technology, and Society Program, Michigan Technological University: Houghton, MI 1988.

Johnson, B.B. and V. Covello. 1987. The Social and Cultural Construction of Risk. Reidel: Amsterdam and New York.

Kasperson, R.E. 1986. "Six Propositions for Public Participation and Their Relevance for Risk Communication," Risk Analysis 6, No. 3: 275-281.

Kasperson, R.E. 1987a. "Public Perceptions of Risk and Their Implications for Risk Communication and Management," in: S.R. McCally (ed), Environmental Health Risks: Assessment and Management. University of Waterloo Press: Waterloo, Canada, pp. 287-296.

Kasperson, R.E. 1987b. "Trust and Credibility: The Central Issue?," In: J.C. Davies, V.T. Covello and F.W. Allen (eds), Risk Communication. The Conservation Foundation: Washing. ton, D.C., pp. 43-46.

Kasperson, R.E. and I. Palmlund. 1987. "Evaluating Risk Communication," unpublished Manuscript. CENTED, Clark University and University of Stockholm: Worcester, MA, and Stockholm, Sweden.

Kasperson, R., O. Renn, P. Slovic et al. 1988. "The Social Amplification of Risk. A Conceptual Framework", Risk Analysis 8, No. 2: 177-187.

Kasperson, R., J. Emel, R. Goble, J.X. Kasperson and O. Renn. 1988. "Radioactive Waste and the Social Amplification of Risk," in: Proceedings of the Waste Management Conference 1987. University of Arizona: Tuscon, AZ.

Lasswell. H.D. 1948. "The Structure and Function of Communication in Society," in: L. Brison (ed), The Communication of Ideas. New York, pp. 32-51.

Lee, T.R. 1986. "Effective Communication of Information about Chemical Hazards," The Science of the Total Environment 51: 149-183.

Lichtenberg, J. and D. MacLean. 1989. "The Role of the Media in Risk Communication," in H. Jungermann, R.E. Kasperson and P.M. Wiedemann (eds), Risk Communication. Nuclear Research Center: Jülich, FRG, pp. 33-48.

Lowrance, W.W. 1976. Of Acceptable Risk: Science and the Determination of Safety. William Kaufman: Los Altos, CA.

Lowry, S. and M.L. DeFleur. 1983. Milestones in Mass Communication Research: Media Effects. Longman: New York and London.

Luhmann, N. 1986. Okologische Kommunikation. Westdeutscher Verlag: Opladen.

Lynn, F.M. 1986. "The Interplay of Science and Values in Assessing and Regulating Environmental Risks," Science, Technology, and Human Values 11, Issue 2, No. 55: 40-50.

Mazur, A. 1984. "The Journalist and Technology: Reporting about Love Canal and Three Mile Island," Minerva 22: 45-66.

Mazur, A. 1987. "Putting Radon on the Public's Risk Agenda," Science, Technology, and Human Values 12 , Nos. 3 and 4, pp. 86-93.

McGuire, W.J. 1985. "Attitudes and Attitude Change," in: G. Lindzey and E. Aronson (eds), Handbook of Social Psychology. Addison-Wesley Publications: Reading, MA.

Meinefeld, W. 1977. Einstellung und Soziales Handeln. Rowohlt: Reinbek, FRG.

Midden, C. 1988. "Credibility and Risk Communication," Paper for the International Workshop on Risk Communication, October 17-20 1988. Nuclear Research Center: Jülich, FRG.

Mileti, D.S., T.E. Drabek and J.E. Haas. 1975. Human Systems in Extreme Environments: A Sociological Perspective. Institute of Behavioral Science, University of Colorado: Boulder, CO.

National Research Council. 1981. Governing Board Committee on the Assessment of Risk. The Handling of Risk Assessments in NRC Reports. National Academy Press: Washington, D.C. 
National Research Council. 1982. Committee on Risk and Decision Making, Risk and Decision Making: Perspectives and Research. National Academy Press: Washington, D.C.

Needleman, C. 1987. "Ritualism in Communicating Risk Information," Science, Technology, and Human Values 12, Nos. 3 and 4, pp. 20-25.

Otway, H., P. Haastrup, W. Cannell, G. Gianitsopoulos and M. Paruccini. 1987. An Analysis of the Print Media in Europe Following the Chernobyl Accident. Report of the Joint Research Center of the Commission of the European Community. EEC: Ispra, Italy, pp. 57-62.

Peltu, M. 1985. "The Role of Communications Media," in: H. Otway and M. Peltu (eds), Regulating Industrial Risks. Butterworth: London, UK, pp. 128-148.

Peltu, M. 1989. "Media Reporting of Risk Information: Uncertainties and the Future," in: H. Jungermann, R.E. Kasperson, and P.M. Wiedemann (eds), Risk Communication. Nuclear Research Center: Jülich, FRG., pp. 11-32.

Perry, R.W., M.K. Lindell, M.R. Greene. 1981. Evacuation Planning in Emergency Management. Lexington Press: Lexington, MA and Toronto, Canada.

Peters, H.P. 1984. Entstehung, Verarbeitung und Verbreitung von Wissenschaftsnachrichten am Beispiel von 20 Forschungseinrichtungen. Nuclear Research Center, Jül-1940. KFA: Jülich, FRG.

Peters, H.P. 1986. "Public Opinion as a Channel of Communication between Science and Other Parts of Society," Paper presented at the 11th World Congress of Sociology, New Delhi: August 18-22, 1986.

Pinsdorf, M.K. 1987. Communicating When Your Company Is Under Siege. Lexington Books: Lexington, MA, and Toronto, Canada.

Plough, A. and S. Krimsky. 1987. "The Emergence of Risk Communication Studies: Social and Political Context," Science, Technology, and Human Values 12, Nos. 3 and 4, pp. 4-10.

Quarantelli, E.L. 1980. Evacuation Behavior and Problems: Findings and Implications from the Research Literature. Disaster Research Center, The Ohio State University: Columbus, Ohio.

Raymond, C.A. 1985. "Risk in the Press: Conflicting Journalistic Ideologies," in: D. Nelkin (ed), The Language of Risk. Sage: Beverly Hills, CA., pp. 97-133.

Rayner, S. 1988. "Muddling through Metaphors to Maturity: A Commentary on Kasperson et al., The Social Amplification of Risk," Risk Analysis 8, No.2: 201-204.

Rayner, S. 1987. "Risk and Relativism in Science for Policy," in: B.B. Johnson and V.T. Covello (eds), The Social and Cultural Construction of Risk. Reidel: Amsterdam and New York.

Rayner, S. and R. Cantor. 1987. "How Fair is Safe Enough? The Cultural Approach to Societal Technology Choice," Risk Analysis 7, 3-13.

Renn, O. 1981. Man, Technology, and Risk, Nuclear Research Center, Jülich, Jül-Spez-115. KFA: Jülich, FRG.

Renn, O. 1983. "Technology, Risk, and Public Perception," Angewandte Systemanalysel Applied Systems Analysis 4, No. 2: 50-65.

Renn, O. 1984. Risikowahrmehmung der Kernenergie (Campus: Frankfurt, FRG, and New York, NY 1984)

Renn, O. 1985. "Risk Analysis - Prospects and Limitations," in: H. Otway and M. Peltu (eds), Regulating Industrial Risks. Butterworth: London, pp. 111-127.

Renn, O. 1988. "Risk Communication: Concepts, Strategies, and Pitfalls," in: Proceedings of the APCA Special Conference in Washington D.C., October 1987. APCA: Washington, D.C., pp. 99-127.

Renn, O. and E. Swaton. 1984. "Psychological and Sociological Approaches to Study Risk Perception," Environment International 10: 557-575. 
Rip, A. 1985. "Experts in Public Arenas," in: H. Otway and M. Peltu (eds), Regulating Industrial Risks. Butterworth: London, pp. 94-110.

Rip, A. 1988. "Should Social Amplification of Risk Be Counteracted? Comment on the Social Amplification of Risk," Risk Analysis 8, No. 2: 193-198.

Rokeach, M. 1969. Beliefs, Attitudes, and Values. California University Press: Berkeley and San Francisco, CA.

Rowe, W.D. 1977. An Anatomy of Risk. Wiley: New York.

Rubin, D.M. 1987. "How the News Media Reported on Three Mile Island and Chernobyl," Communication 37, No.3: 42-57.

Sandmann. P.M. 1989. "Hazard Versus Outrage: A Conceptual Frame for Describing Public Perception of Risk," in: H. Jungermann, R.E. Kasperson, and P.M. Wiedemann (eds), Risk Communication (Nuclear Research Center: Jülich, FRG, pp. 163-168.

Sandman, P.M., N.D. Weinstein and M.L. Klotz. 1987. "Public Response to the Risk from Geological Radon," Communication 37, No. 3: 93-108.

Shannon, C.E. and W. Weaver. 1949. The Mathematical Theory of Communication. The University of Illinois Press: Urbana, IL.

Shoemaker, P.J. 1987. "Mass Communication by the Book: A Review of 31 Texts," Communication 37, No. 3: 109-133.

Singer, E. and P. Endremy. 1987. "Reporting Hazards: Their Benefits and Costs," Communication 37, No. 3: 10-26.

Slovic, P. 1987. "Perception of Risk," Science 236, No. 4799, pp. 280-285.

Slovic, P. 1987. "Informing and Educating the Public about Risk," in: P.R. Kleindorfer and H.C. Kunreuther (eds), Insuring and Managing Hazardous Risks: From Seveso to Bhopal and Beyond. Springer: Berlin, FRG, pp. 307-332.

Slovic P., B. Fischhof and S. Lichtenstein. 1982. "Why Study Risk Perception? Risk Analysis 2: 83-94.

Sood, R., G. Stockdale and E.M. Rogers. 1987. "How the News Media Operate in Natural Disasters," Communication 37, No. 3: 27-41.

Thomas, L.M. 1987. "Why We Must Talk About Risk," in: J.C. Davies, V.T. Covello and F.W. Allen (eds), Risk Communication. The Conservation Foundation: Washington, D.C., pp. 19-25.

Wicker, A.W. 1979. "Attitudes vs Actions: The Relationship of Verbal and Behavioral Responses to Attitude Objects," Journal of Social Issues 22: 41-78.

Wilkins, L. and P. Patterson. 1987. "Risk Analysis and the Construction of News," Communication 37, No. 3: 80-92.

Zimmermann, R. 1987. "A Process Framework for Risk Communication," Science, Technology, and Human Values 12, Nos. 3 and 4: 131-137. 